\title{
AS CONTRIBUIÇÕES DO PIBID - LÍNGUA PORTUGUESA PARA A FORMAÇÃO DA IDENTIDADE DOCENTE: UM PANORAMA DAS ATIVIDADES REALIZADAS ${ }^{1}$
}

\author{
Gabriely Rosa Caetano ${ }^{2}$ \\ Alícia Durães de Faria ${ }^{3}$ \\ Arianny Cristina Chaves Lacerda ${ }^{4}$ \\ Gabriela da Silva Pires ${ }^{5}$
}

\begin{abstract}
Resumo: Este artigo pretende apresentar um panorama de atividades desenvolvidas em um Colégio de Aplicação da Zona da Mata Mineira, por meio do Programa Institucional de Bolsa de Iniciação à Docência (Pibid), como também as reflexões e aprendizados decorrentes de suas práticas. Tendo como embasamento teórico as discussões de Oliveira (2017), Ferreira (2005), Kunz et al. (2011), dentre outros, são apresentadas três práticas de atuação: a primeira delas aborda a Literatura, mais especificamente, poesias; a segunda constitui-se em um trabalho com o gênero textual crônica; a terceira evidencia a dinâmica de esquema de rodízio entre turmas. O trabalho visa divulgar a constituição dessas ações, as contribuições para a escola, seus estudantes, professores e para nós, pibidianas, com ênfase na construção de nossa identidade docente. Para tanto, trazemos discussões a respeito do contexto de atuação, da necessidade de adaptação às dificuldades dos estudantes e do trabalho com Gêneros Textuais e Literatura.
\end{abstract}

Palavras-chave: Identidade docente. Pibid. Metodologias didáticas. Gêneros Textuais. Literatura.

Abstract: This article intends to introduce a panorama of activities developed at an Application High School from Minas Gerais, enabled by Pibid (Institutional Teaching Initiation Scholarship Program), as well the reflections and learnings provided by them. Having as theoretical basis the discussions by Oliveira (2017), Ferreira (2005), Kunz et al. (2011), among others, three performance practices are presented: the first one approaches Literature, specifically, poetry; the second one is a work developed with the textual genre

${ }^{1}$ O presente trabalho foi realizado com apoio da Coordenação de Aperfeiçoamento de Pessoal de Nível Superior - Brasil (Capes), por meio do Programa Institucional de Bolsa de Iniciação à Docência/Universidade Federal de Viçosa (2018/2020).

${ }^{2}$ Graduanda no Departamento de Letras vinculado ao Centro de Ciências Humanas, Letras e Artes da Universidade Federal de Viçosa (UFV). Viçosa/MG. Brasil. Endereço eletrônico: grosacaetano@gmail.com.

${ }^{3}$ Graduanda no Departamento de Letras vinculado ao Centro de Ciências Humanas, Letras e Artes da Universidade Federal de Viçosa (UFV). Viçosa/MG. Brasil. Endereço eletrônico: aliciaduraes11@gmail.com.

${ }^{4}$ Graduanda no Departamento de Letras vinculado ao Centro de Ciências Humanas, Letras e Artes da Universidade Federal de Viçosa (UFV). Viçosa/MG. Brasil. Endereço eletrônico: arianny.lacerda@ufv.br.

${ }^{5}$ Professora Adjunta do Departamento de Letras vinculado ao Centro de Ciências Humanas, Letras e Artes da Universidade Federal de Viçosa (UFV). Viçosa/MG. Brasil. Endereço eletrônico: gabriela.pires@ufv.br. 
chronicle; the third one exhibits the dynamic of a rotation scheme between the classes. The work intends to publicize the nature of these actions, the contributions for the school, the students, the teachers and for us, the Project participants, emphasizing the construction of our teaching identity. For that, the article discusses the context practices were developed, the need to adapt to students' difficulties and the work with Textual Genres and Literature.

Keywords: Teaching Identity. Pibid. Didactic Methodologies. Textual Genres. Literature.

\section{Introdução}

O Programa Institucional de Bolsa de Iniciação à Docência (Pibid), por meio das atividades que proporciona na escola, estimula a curiosidade e a autonomia de professores em formação. Por conseguinte, essas características tornam esses profissionais capazes de ampliarem suas perspectivas acerca do fazer docente e fortalecem a profissão professor (OLIVEIRA, 2017). Nessa perspectiva de amplificação de pontos de vista sobre a docência, viabilizada pela disposição de bolsas da Coordenação de Aperfeiçoamento de Pessoal de Nível Superior (Capes) aos licenciandos, o que propomos neste artigo é evidenciar um panorama das atividades realizadas com gêneros textuais e com a literatura em um Colégio de Aplicação de Ensino Médio, na Zona da Mata Mineira, e, sobretudo, fomentar reflexões sobre a importância da atuação no Pibid-UFV para a construção da identidade de licenciandas como futuras professoras.

Além disso, concomitantemente aos resultados possibilitados a estudantes da graduação e a professores-supervisores do programa, pretendemos proporcionar reflexões sobre o papel docente no desenvolvimento de leitores críticos. Para isso, respaldamo-nos nas discussões feitas por Abreu (2017, p. 73), a qual, refletindo sobre as ideias de Kleiman (2002), aponta que "quanto mais diversificada for a experiência de leitura do aluno e quanto mais familiaridade ele tiver com a estrutura de textos descritivos, narrativos, expositivos, mais fácil será para ele perceber as relações entre estrutura e a informação vinculada ao texto.”

Acreditamos também na relevância de divulgar os benefícios que o Programa propicia aos professores em formação, principalmente, no que se refere à construção da identidade docente, ao passo que são realizadas discussões teóricas, regência e observação de aulas, correção de exercícios e sessões de atendimentos aos alunos. Da mesma forma, julgamos crucial difundir as atividades executadas e suas respectivas reflexões para que outros estudantes se motivem a participar do processo de expansão teórico-prático proporcionado pelo Pibid. 
Os subprojetos do Programa são constituídos por um grupo de licenciandos, orientado geralmente por um professor da educação básica, que atua como supervisor, e um professor do ensino superior, ao qual é atribuída a função de coordenador de área. No cenário em que atuamos, de forma específica, a equipe foi composta por uma professora-supervisora bolsista e três voluntárias ${ }^{6}$, além de uma coordenadora. Dessa forma, como todas as professoras e as graduandas atuantes nas atividades a serem apresentadas são mulheres, optamos por utilizar o gênero feminino quando referenciarmos esses dois grupos. Utilizaremos o gênero masculino, portanto, para os demais casos.

Logo, este trabalho evidenciará o desenvolvimento das atividades em seções. $\mathrm{Na}$ próxima seção, apresentamos uma breve discussão acerca das contribuições do Programa para a construção de identidade profissional, bem como sobre o trabalho com a literatura na escola. Na seção três, relatamos nossas experiências com o planejamento e a execução de atividades com poesias, arte, crônicas, correções, atendimentos e rodízio entre as turmas, além de apontar reflexões sobre a necessidade que o professor tem de avaliar o próprio contexto de atuação e de adaptar seu planejamento conforme as dificuldades trazidas pelos alunos. Por último, ponderamos acerca dos resultados obtidos ao longo da participação no Pibid.

\section{Contribuições do Pibid para o trabalho com a Língua Portuguesa}

Compreender o funcionamento de uma sala de aula enquanto professor em formação é indispensável para qualquer curso de licenciatura, visto o objetivo de saber articular teorias e práticas; mas poder ter este primeiro contato através do Pibid é, certamente, um processo de aprimoramento profissional e pessoal. Isso porque o Pibid "promove a indissociabilidade entre ensino e pesquisa, de modo que os acadêmicos colocam em prática o que estudam durante o curso de graduação" (KUNZ et al., 2011, p. 156) e, a partir dessa experiência prática e das reflexões proporcionadas por ela, os pibidianos tornam-se aptos, também, a avaliar criticamente a própria teoria. Desse modo, as discussões acerca da realidade das escolas brasileiras passam a fazer parte de todo o percurso acadêmico dos estudantes e não ficam restritas aos estágios obrigatórios, surgindo como uma possibilidade a mais de aprimorar os estudos e as práticas - de forma "espontânea", sem a pressão de avaliações e notas. A experiência do Pibid mostra-se, portanto, significativa, visto que, como aponta

\footnotetext{
${ }^{6}$ Agradecemos às professoras supervisoras: Ofélia Maria Imaculada (bolsista); Anita Maria Ferreira da Silva, Camila Rita Lelis e Silvana Marchesani (supervisoras voluntárias).
} 
Oliveira (2017, p. 931), “[...] o diferencial na formação docente é a integração com outros projetos e atividades de profissionalização, as quais denotam e dão corpo à qualidade de trabalho formador ao longo da licenciatura".

Ademais, é válido ressaltar que o Projeto também permite maior diálogo entre a escola e a própria estrutura da graduação, pois, com esse contato, surge a possibilidade de identificar certas demandas e possíveis soluções, de forma a incrementar a matriz da graduação, seja nas disciplinas de Ensino, seja na troca de experiências a respeito de metodologias didáticas nas aulas teóricas. Kunz et al. também defendem esse ponto de vista ao afirmarem que

O curso e a coordenação do subprojeto, em contato com o locus escolar, percebem a realidade atual da educação, podendo diagnosticar suas carências e suas potencialidades. Essa experiência resulta, então, em uma forma de pesquisa de campo, que permite a reflexão sobre o próprio curso de graduação, no sentido de que os egressos devem estar preparados para atuar na realidade fora do espaço acadêmico (KUNZ et al., 2011, p. 157, grifo das autoras).

Além disso, ressaltamos que, segundo as autoras Tavares, Andrade e Pacheco (2017, p. 136), “"analisar e acompanhar a produção de cada aluno' levando em consideração suas particularidades torna-se, sem a contribuição do projeto, um trabalho difícil de ser realizado em turmas com 50 ou mais estudantes". Assim, pode-se notar como o Pibid surge como um excelente apoio para os professores da educação básica, uma vez que eles recebem uma leva de discentes dispostos a aprender e auxiliar no que for preciso, o que se converte em maior disponibilidade para atender as especiais demandas dos alunos nas escolas.

Também é válido apontar que o Pibid auxilia na aquisição da chamada "coerência pragmática", conceito de Chartier (2007, apud MENDONÇA, 2018, p. 256) e que se baseia, principalmente, no desenvolvimento de um conhecimento a partir de experiências e dos "saberes da ação", como reinventar-se no preparo das aulas, de forma a conciliar o tempo pedagógico, o perfil da sala de aula, a relevância do tema, entre outros. Desse modo, os pibidianos finalizam a graduação com um "olhar do professor" já em processo de desenvolvimento, e "se definem como indivíduos sociais e constroem suas identidades na medida em que interagem com professores e colegas e com as próprias experiências educacionais" (OLIVEIRA, 2017, p. 916).

Como é possível perceber, o Pibid surge como uma oportunidade diferenciada tanto para as escolas quanto para os professores em formação, disponibilizando para esses um 
ambiente propício para o desenvolvimento de práticas escolares e capacitação profissional e pessoal. De acordo com Oliveira (2017, p. 920-921), ao passo que participam do Projeto, os licenciandos atribuem uma nova significação às crenças preconcebidas no que toca ao papel do docente, fazendo com que "ao invés de reforçarem a imagem decadente do professor", compartilhem experiências a fim de reconstruir o "sentido da aprendizagem, da escola e da educação".

Ainda segundo Oliveira (2017), essa ressignificação segue acompanhada da “autonomia profissional”, pois, após as reflexões causadas pela identificação com a docência, urge o desejo de ação e mudança da realidade experienciada, levando para as escolas profissionais capacitados e determinados. Com efeito, a experiência com o Pibid vem se mostrando eficaz inclusive como contribuição positiva para reforçar uma imagem mais dinâmica e engajada do professor.

\section{A prática docente sob uma perspectiva pibidiana: apresentando ações e possibilidades}

Um enlaçamento de poesia e intervenção

O projeto artístico e literário "Instalações Poéticas: A mulher na poesia" foi realizado com o intuito de ambientar a linguagem poética aos alunos da primeira série do Ensino Médio. Caracterizou-se, portanto, em um trabalho interdisciplinar estimulador da ação, entre as disciplinas de Literatura e Arte, como alternativa para modificar a maneira de explorar o gênero poético na escola. Dessa forma, o conjunto de práticas a serem expostas neste segmento consiste na ressignificação do texto para a linguagem artística, ou, mais especificamente, para a realização de intervenções. Vale ressaltar, ainda, que o projeto foi desenvolvido pelas professoras das disciplinas mencionadas e, ao longo desta atividade, a nossa participação enquanto pibidianas ocorreu de forma mais observadora do que interativa, uma vez que o nosso contato com a escola ainda era recente.

Conforme mencionado por Kunz et al. (2011), o trabalho com textos literários, na sala de aula, deve ser realizado de forma aprofundada, isto é, para além do mero consumo de informações. O desenvolvimento dessa prática, então, deve permitir ao aluno a reflexão sobre a sua própria realidade, além de agregar conhecimento cultural, como também possibilitá-lo a manifestação de si mesmo. No entanto, ao lidar com os contextos reais da escola, um dos obstáculos para o ensino da literatura é o fato de o professor deparar-se com salas cheias de alunos, o que implica a dificuldade de fazer com que a compreensão dos textos seja efetiva 
para todos. Ademais, Abreu (2017) afirma que o trabalho com a literatura na escola, por vezes, torna-se superficial, considerando as demandas institucionais que existem sobre o professor.

A autora ressalta ainda que "no contexto da sala de aula a leitura é promovida como uma prática mecânica e rotineira", e, por isso, a "desconstrução desse método é essencial para que possamos efetuar mudanças no sentido de orientar os sujeitos a obterem dessas leituras um pensamento crítico em frente ao mundo" (ABREU, 2017, p. 76-77). Assim, de modo a promover a interpretação crítica do gênero poético, a criação de um projeto que interrompesse com essa metodologia de trabalho na sala de aula, bem como possibilitasse o envolvimento dos alunos, foi de grande relevância. Com a atividade, os alunos puderam construir sentidos aprofundados sobre os poemas e, ainda, conhecer outros textos apresentados pelos colegas. Dessa forma, o projeto estimulou a participação ativa e a colaboração entre eles, possibilitando a compreensão factual do gênero.

Trabalhar com poesias justifica-se, enfim, por possibilitar aos alunos determinada autonomia para criarem suas interpretações, devido a seus aspectos constituintes subjetivos, que a tornam "objeto único e particularmente complexo" (ABREU, 2017, p. 76), como também nos diz Saraiva (2001, p. 27 apud KUNZ et al., 2011, p. 160):

Por ser expressão artística, o texto literário extrai dos processos históricopolítico-sociais uma visão da existência humana que transcende o tempo de sua concepção e instiga o leitor sob forma de perguntas que o levam a analisar seu próprio tempo. Como resultado da interação receptiva e criadora do autor diante da práxis literária e diante do mundo, o texto exige, pois, para instituir-se a recuperação ativa e criadora do leitor. Ela transita dos princípios constitutivos próprios do texto para o contexto extraliterário; do mundo da significação textual, para o sentido do mundo (KUNZ et al., 2011, p. 160).

Os objetivos principais desse projeto consistiram em incentivar a leitura de poesias, fomentar o espírito crítico dos alunos e sensibilizá-los com relação à leitura de poesias, uma vez que elas possuem amplas significações, as quais permitem ao autor "expressar toda e qualquer emoção que anseie libertar" (ABREU, 2017, p. 74). Ademais, o conceito de intervenção foi trabalhado com a finalidade de incentivar os alunos a pensarem sobre a arte e o seu impacto no cotidiano. 
Visando atrelar uma temática contemporânea a uma problemática social, as professoras julgaram pertinente que os alunos selecionassem poemas escritos por autores brasileiros, cujo tema fosse a figura feminina, para criarem uma intervenção artística relacionada com algum aspecto presente na poesia. Por uma questão logística, cada uma das quatro turmas foi dividida em grupos menores. Assim, todos os poemas foram previamente apresentados às professoras, tal qual o espaço da escola que desejavam ocupar, a fim de evitar a repetição de textos e dos lugares.

Em seguida, foi ministrada uma aula que serviu para a exploração do conceito de intervenção, o qual é composto por múltiplas significações. Entretanto, para esse trabalho tomou-se como definição a ideia do âmbito artístico de intervir sobre um espaço, durante determinado tempo e lugar, para

promover alguma transformação ou reação, no plano físico, intelectual ou sensorial [...] provocar reações e transformações no comportamento, concepções e percepções dos indivíduos, um componente de subversão ou questionamento das normas sociais, [...] a interrupção do curso normal das coisas através da surpresa, do humor, da ironia, da crítica, do estranhamento (INTERVENÇÃ̃, 2019).

No primeiro dia da exposição, que ficou instalada por cerca de duas semanas na escola, os alunos montaram suas intervenções durante a manhã, de forma que todas as pessoas que ali chegassem, seja para trabalhar ou estudar, sentissem o impacto de terem suas rotinas modificadas. Assim, vários espaços da escola foram contemplados com uma instalação, o que consequentemente deixou o prédio do colégio alterado e atraiu a atenção das pessoas que estiveram presentes no local. Por conseguinte, além da interação dos próprios alunos com as criações artísticas dos colegas, professores, funcionários e estudantes de outras séries também puderam se aproximar das linguagens literária e artística.

Por último, cada grupo apresentou para sua respectiva turma o poema motivador da intervenção, declamando-o, analisando-o e justificando sua escolha. Entre os textos apresentados, podemos citar Às seis da tarde (Marina Colasanti) ${ }^{7}$, Com licença poética $(\text { Adélia Prado })^{8}$ e Mulher ao espelho (Cecília Meireles) ${ }^{9}$. Dessa maneira, puderam discutir e

\footnotetext{
${ }^{7}$ Cf. COLASANTI, Marina. Às seis da tarde. Disponível em: https://www.escritas.org/pt/t/10306/as-seis-datarde. Acesso em: 15 mar. 2021.

${ }^{8}$ Cf. PRADO, Adélia. Com licença poética. Disponível em: https://wp.ufpel.edu.br/aulusmm/2020/11/11/comlicenca-poetica-adelia-prado/. Acesso em: 15 mar. 2021.
} 
explorar os temas abordados, tanto no que diz respeito às violências que acometem o gênero feminino e os padrões estéticos impostos pela sociedade quanto o que é concernente à ocupação das mulheres nos diversos espaços sociais. Ademais, o trabalho permitiu a relação com outros gêneros textuais, uma vez que, em suas intervenções, determinados alunos montaram a obra com o apoio de notícias e recados de empoderamento para o público.

A exposição das intervenções resultou em emoção por parte dos espectadores, inclusive das participantes do Pibid. Essa provocação da arte demonstra, portanto, a relação de intimidade e poesia apontada por Abreu (2017, p. 75), pois para a autora a "poesia não exige somente atenção para correr os olhos pelas palavras, ela exige de nós uma relação de intimidade com cada palavra ali descrita, para que possamos recriar em nós sensações semelhantes àquelas em que o autor mergulhou ao escrever." Assim sendo, consideramos que, ao vivenciar, por meio do Pibid, situações positivas e comoventes como essa, também somos incentivadas a nos construirmos enquanto profissionais engajadas na formação de novos leitores críticos.

Em síntese, as contribuições desse acompanhamento do projeto nos possibilitaram bastante reflexão quanto à forma inovadora de se trabalhar o gênero poético. Nessa perspectiva, o nosso envolvimento ocorreu de forma a analisar todo o processo de construção, desde o planejamento à conclusão. Logo, percebemos que é possível promover o interesse dos alunos pelos gêneros literários, desenvolvendo atividades que visam à compreensão textual em espaços alternativos, de forma lúdica e prazerosa, além de proporcionar integração com outras disciplinas do currículo escolar, como foi o caso da Literatura e da Arte.

\section{A crônica: a prosa é curta, o trabalho não}

Parte das atividades do Pibid de Língua Portuguesa com as turmas da segunda série do Ensino Médio foi voltada, principalmente, para o gênero textual crônica. Este trabalho foi desenvolvido por nós, pibidianas, em interação com as professoras supervisoras e a coordenadora de área. Como resultado, tivemos uma experiência extremamente significativa permeada por reflexões acerca de metodologias didáticas. Isso porque a crônica surge nas salas de aulas brasileiras como um verdadeiro desafio para os professores, visto que, apesar dos estudos sobre tipos e gêneros linguísticos aumentarem, há ainda a problemática da

9 Cf. MEIRELES, Cecília. Mulher ao espelho. Disponível em: http://www.literaturabrasileira.com/2016/02/aoespelho.html. Acesso em: 15 mar. 2021. 
PERcursos Linguísticos • Vitória (ES) •v. 11 •n. 27 • 2021 • ISSN: 2236-2592 •

Dossiê: Pibid e RP na formação de professores em Letras •

dificuldade de se classificar certos textos, principalmente pelas suas estruturas fluidas e não bem definidas (FERREIRA, 2005).

Desse modo, as próprias professoras verificaram que, em seus diversos anos de trabalho com a crônica, os alunos tendiam a apresentar dificuldades diante desse gênero tão complexo; o que é uma preocupação extremamente válida, pois, como dito, a caracterização da crônica como gênero textual é ainda uma discussão inacabada. Com seu caráter literário, mas vinculada ao jornal, a crônica aparenta se dividir entre dois mundos, e, não à toa, Artur da Távola a define como: “a literatura do jornal. O jornalismo da literatura. É a pausa de subjetividade, ao lado da objetividade da informação do restante do jornal. Um instante de reflexão, diante da opinião peremptória do editorial" (TÁVOLA, 2001). Dessa maneira, ainda que os alunos estejam familiarizados com textos híbridos, como aqueles presentes nas mídias sociais, absorver a mescla de tons proporcionada pela crônica pode ser desafiador, visto que, muitas vezes, eles não estão habituados com o gênero referido.

Todavia, apesar das aparentes dificuldades de trabalhar com uma estrutura de texto tão complexa, a crônica também surge nas aulas como um excelente objeto de estudo para o professor e para os estudantes. Isso porque ela traz, para o primeiro, a facilidade de se apresentar através de textos curtos, que atendem à necessidade do tempo pedagógico, e que podem criar diversas discussões significativas; e para os estudantes, a crônica pode surgir como uma porta de entrada para a leitura de fruição, por ser um texto curto e geralmente divertido, por isso "vale ressaltar a satisfação de leitura que o gênero traz aos nossos alunos, principalmente porque lhes são apresentados com mais frequência os textos humorísticos desse gênero" (FERREIRA, 2005, p. 11). Desse modo, nota-se o quão desafiador e, ao mesmo tempo, prazeroso pode ser o trabalho com a crônica, pois além de beneficiar o professor no que diz respeito ao tempo pedagógico, este gênero textual ainda é capaz de atrair os alunos e motivá-los.

Posto isso, ao começar os estudos para preparar o material didático, optamos por trabalhar a crônica contrapondo-a com o gênero textual conto, visto que, aparentemente, a maior dificuldade dos estudantes era a de diferenciar esses gêneros, uma vez que é inegável "a existência de uma fronteira imprecisa entre a crônica e o conto. O que faria uma crônica ser chamada de conto, como os críticos o fazem? [...] A resposta poderia estar no suporte que veicula originariamente a crônica? Ou na evolução histórica da crônica?” (FERREIRA, 2005, p. 13, grifo da autora). Após a leitura da resenha que Edgar Allan Poe escreveu sobre 
Twice-told Tales de Nathaniel Hawthorne, como parte do material de pesquisa, o trabalho foi nomeado como a prosa curta, que, segundo Poe, refere-se aos textos que podem ser lidos de uma vez, numa "sentada só", como é o caso dos gêneros que seriam trabalhados.

Assim, após estudos e discussões, planejamos duas aulas, sendo a primeira teórica e a outra mais interativa, baseando-nos, principalmente, nos estudos de Jorge de Sá, em $A$ Crônica. O ponto de partida foi tipologia textual, com um breve momento de revisão do assunto, para, em seguida, abordar os gêneros textuais, suas mutabilidades, entrelaçamentos e como eles surgem de acordo com as necessidades sociocomunicativas. Destacamos, principalmente, o suporte como contraponto entre conto e crônica, apontando as diferentes origens entre eles.

A crônica trabalhada em sala foi Abraço caudaloso do escritor Gregório Duvivier, na qual foram destacadas as principais características do gênero, como a subjetividade, a presença do humor, o fato desencadeador do texto (o estalo), assuntos frívolos, o diálogo com o leitor e a própria forma bela de desenvolver a temática. Apresentamos ainda o texto de Artur da Távola Literatura de Jornal (O que é a Crônica) com o intuito de explicitar o que seria o "falar bonito" da crônica. Na segunda aula, o texto trabalhado foi $O$ Lixo de Luis Fernando Verissimo para que fosse possível verificar se os alunos eram capazes de identificar o gênero da obra. Ademais, a importância da leitura para conhecer o gênero mais a fundo foi reforçada com dicas de textos e autores.

Para a proposta de produção, foram selecionadas algumas notícias, como Caixa deposita $R \$ 2,28$ bilhões por engano e mulher devolve o dinheiro ${ }^{10}$ e Em sessão de 'Vingadores: Ultimato', homem dá spoilers e provoca briga, em São Gonçalo ${ }^{11}$, de forma que os estudantes construíssem as suas crônicas a partir do texto que mais se interessassem. A tarefa de avaliar os textos dos alunos mostrou-se, obviamente, desafiadora, pois

a maioria dos autores da área de Teoria da Literatura, por exemplo, trazem como exemplo de gênero narrativo a crônica, mas quando partem para a definição da mesma mostram-se convencidos de que há outras formas de estruturá-la, e que isso é, inclusive, característica própria da crônica (FERREIRA, 2005, p. 13).

\footnotetext{
${ }^{10}$ Cf. MENDES, Eduardo. Caixa deposita R $\$ 2,28$ bilhões por engano e mulher devolve o dinheiro. Seu Crédito Digital. 7 mai. 2019. Disponível em: https://seucreditodigital.com.br/caixa-deposita-bilhoes-mulher-devolvedinheiro/. Acesso em: 15 mar. 2021.

${ }^{11}$ Cf. QUEIROGA, Louise. Em sessão de 'Vingadores: Ultimato', homem dá spoilers e provoca briga, em São Gonçalo. Extra, 27 abr. 2019. Disponível em: https://extra.globo.com/noticias/rio/em-sessao-de-vingadoresultimato-homem-da-spoilers-provoca-briga-em-sao-goncalo-23627715.html. Acesso em: 15 mar. 2021.
} 
Dessa maneira, juntamente com as professoras, os critérios para a avaliação foram cuidadosamente selecionados, de forma que todas as corretoras se atentassem aos mesmos parâmetros, pois cada texto seria corrigido por uma pibidiana e por uma professora. Todavia, a maioria dos textos apresentados pelos estudantes aproximavam-se de contos, e, em uma tentativa de abordagem diferente, apresentamos, na terceira aula, textos dos próprios alunos. Com isso, foi realizada uma leitura coletiva das produções para explorar as diferenças entre um gênero e o outro. É válido ressaltar que digitamos os textos para que nenhum aluno fosse identificado e que levar os textos dos próprios estudantes foi um diferencial, pois eles se sentiram mais próximos das obras e até mais motivados.

Segundo Clein (2007, p. 290), "é preciso, enquanto professor, ter o olhar atento para o outro e, a partir disso, buscar encontrar estratégias de trabalho que minimizem os percalços que impedem que o processo de ensino-aprendizagem se dê de modo satisfatório" e, dessa forma, foram criados inúmeros atendimentos individuais, com o intuito de trabalhar cada um dos textos com seus respectivos autores. Esses momentos aconteciam no espaço escolar, no contraturno, e consistiam numa análise das produções, realizadas pelos alunos, com orientação das pibidianas.

Por fim, após dois meses dedicados aos estudos sobre crônica, vimo-nos diante de textos bem escritos, com alunos muito mais seguros das suas capacidades de produção e alguns novos leitores, o que tornou notória a importância do contato dos alunos com o texto literário, visto que "essa dificuldade em produzir o gênero certo é uma consequência da falta de contato que o aluno teve com o gênero crônica" (CLEIN, 2007, apud FERREIRA, 2011, p. 292-293).

Dessa forma, pode-se notar o quão desafiador foi este trabalho e o quanto ele nos preparou para o que está por vir no caminho da docência, seja desenvolvendo metodologias e abordagens didáticas, seja aprendendo a lidar e contornar as dificuldades dos alunos; permitindo-nos experimentar da "coerência pragmática" dos professores, que se baseia, principalmente, na experiência e nos "saberes da ação" (CHARTIER, 2007, apud MENDONÇA, 2018, p. 256). Além da importância do Projeto na nossa formação docente, ressaltamos a relevância do próprio Pibid na escola, principalmente no que diz respeito aos atendimentos individuais, tão indispensáveis nos resultados satisfatórios que conseguimos, 
pois, pela carga horária que eles exigiram, não seriam possíveis, infelizmente, sem a presença de nós, pibidianas.

\section{Ampliando olhares e perspectivas: o rodízio entre turmas}

Sabemos que os conteúdos mudam de uma série para outra, que a metodologia pela qual o professor optar faz toda diferença; e, ainda, que o professor, ao planejar seu trabalho, precisa levar em consideração a faixa etária, os conhecimentos anteriormente construídos e os fatores que permeiam a vida escolar dos seus alunos. Outro fator importante é que cada professor é diferente, possuidor de sua própria identidade docente, de preferências metodológicas e de interação com a turma, de traços de personalidade, entre outros.

Considerando que, na escola em que atuamos, a equipe era composta por uma professora da educação básica, vinculada ao Pibid, e outras três, que atuaram de forma voluntária, além de dez graduandos e uma coordenadora de área, foi criada uma dinâmica que contemplasse a nossa atuação em todas as séries da escola, sob a orientação de cada uma das professoras. Assim, concluímos que essa seria a forma de trabalho mais vantajosa. Vale ressaltar também que cada professora de Língua Portuguesa é responsável por uma série (primeira, segunda ou terceira do Ensino Médio), juntamente com a professora de Literatura, que trabalha nas três. Concretizou-se, então, o rodízio semestral entre as séries.

O Programa Institucional de Bolsa de Iniciação à Docência contribui para a formação docente de várias formas, como, por exemplo, através de eventos, cursos e, principalmente, ao possibilitar que os licenciandos, conforme nos diz Oliveira (2017), experimentem e validem ativamente modos atuais de exercer a prática docente. Por meio do Pibid, os estudantes de graduação têm a oportunidade de vivenciar a realidade da educação básica, ou melhor, as suas multifaces, pois a conjuntura da sala de aula pode variar muito de uma escola para outra e até mesmo dentro da mesma escola.

Há variação dentro de uma mesma escola, porque as séries são diferentes, com conteúdos diferentes a serem trabalhados, em turmas distintas, compostas por estudantes únicos, por professores que, por sua vez, têm abordagens singulares. Assim, a respeito da relevância da interação com diferentes abordagens didáticas e identidades docentes, proporcionadas pelo Pibid, Oliveira (2017, p. 916) pontua que 
[...] ao desenvolverem suas práticas e realidades acerca da docência, da licenciatura e do trabalho profissional, os participantes do PIBID automaticamente se definem como indivíduos sociais e constroem suas identidades na medida em que interagem com professores e colegas e com as próprias experiências educacionais. (OLIVEIRA, 2017, p. 916).

Dessa forma, um planejamento que possibilitasse a atuação nas mais variadas séries e sob a orientação de professoras diferentes proporcionou maior conhecimento sobre as realidades das turmas e mais aprendizado para as professoras em formação. $\mathrm{O}$ esquema de rodízio realizado durante nosso período no Pibid é um exemplo de estratégia que obteve resultado positivo, já que contribuiu para uma experiência ainda mais produtiva. $\mathrm{O}$ trabalho em conjunto e as ações desenvolvidas entre pibidianas e professoras supervisoras consolidaram um vínculo de aprendizagens mútuas, reforçando positivamente a ambientação no futuro espaço de trabalho das graduandas.

Durante a execução do rodízio, foi possível perceber a diferença e comparar, de forma positiva, os conteúdos, as metodologias escolhidas pelas professoras, os recursos didáticos pelos quais optavam e suas formas de interagir com as turmas. Notamos, ainda, diferenças entre as turmas de uma mesma série - o que requer atenção do professor ao perfil da turma ao trabalhar um conteúdo - e também de uma série para outra. A adaptação à nova escola pela qual os estudantes passam na primeira série, a chegada dos vestibulares e da formatura para os da terceira série, em suma, o contexto no qual os alunos estão inseridos demonstrou ser um fator importante e que não pode ser desconsiderado pelo professor.

Em alguns casos, foi possível perceber a evolução dos estudantes de uma série para a outra e a adaptação com uma nova professora: dois grupos do rodízio puderam acompanhar as mesmas turmas por dois semestres seguidos, em duas séries diferentes, isto é, aqueles que acompanharam a primeira e a segunda série em seu primeiro semestre de atuação, ao passar, devido ao rodízio, para a série seguinte, encontraram as mesmas turmas. Já o grupo que começou atuando na terceira série, além do acompanhamento das professoras, teve contato com mais perfis de turmas, visto que, a cada semestre, conhecia novos alunos.

Sendo assim, é notório que o rodízio constitui-se na possibilidade de ampliar ainda mais as contribuições proporcionadas pelo Pibid, uma vez que, por meio dele, é possível que os graduandos observem e aprendam com professores e práticas diferentes, comparando-as criticamente. O rodízio proporciona, também, a atuação em uma maior variedade de turmas, as quais possuem conteúdos, necessidades e contextos diferentes que exigem, do professor, 
PERcursos Linguísticos • Vitória (ES) •v. 11 •n. 27 • 2021 • ISSN: 2236-2592 •

Dossiê: Pibid e RP na formação de professores em Letras •

abordagens distintas. Através dessas ricas experiências, o professor em formação vai construindo a sua identidade docente.

\section{À guisa de conclusão}

Por meio do Pibid, observamos, planejamos e ministramos aulas, fizemos correções textuais, realizamos atendimentos individuais com os alunos do colégio no qual atuamos, entre outras ações. Algumas dessas atividades compartilhamos aqui neste artigo e, por meio delas e das demais realizadas, desenvolvemos nossa identidade docente e construímos saberes que, com certeza, utilizaremos futuramente em nossa atuação profissional.

Aprendemos a desenvolver metodologias e abordagens de forma a facilitar o aprendizado e suprir as necessidades pedagógicas dos estudantes. Notamos que é possível e benéfico inovar nas maneiras de se trabalhar os conteúdos escolares, como, por exemplo, ao extrapolar o espaço da sala de aula, levando manifestações artísticas para toda a escola. Elaborar um planejamento dinâmico e promover um maior interesse pelas atividades propostas, bem como explorar a criatividade dos discentes mostraram-se estratégias com resultados positivos. Desenvolvemos, ainda, a habilidade de planejar aulas, ministrá-las e realizar correções textuais, o que resultou em maior desenvoltura durante as aulas e ao interagir com os alunos, considerando sempre as especificidades de cada turma e seus contextos.

Em nossa atuação, sempre tivemos ao nosso lado as orientadoras e outros colegas pibidianos, com os quais agregamos conhecimento e enriquecemos nossa prática, tanto observando-os, quanto por meio de discussões sobre teoria e prática docente. Nada disso seria possível sem o Pibid, que proporciona a licenciandos do país todo a inserção em seu futuro ambiente de trabalho, a articulação entre teoria e prática e reflexões, a construção de identidade e saberes docentes, além de beneficiar a comunidade escolar.

Assim como as trocas com outros professores — atuantes e em formação — foram produtivas para nós, ao compartilhar nossas experiências, almejamos contribuir para que outros professores reflitam sobre os assuntos aqui abordados e, quiçá, outros mais. Em suma, pretendemos que essas experiências, de alguma forma, auxiliem e inspirem outros docentes, ou futuros docentes, a se reinventarem, através da aquisição de novos conhecimentos, assim como aprendemos em nossa participação no Programa. 


\section{Referências}

ABREU, Kelly Mara de. O ensino da arte literária sob o olhar do PIBID. In: COELHO, Fábio André Cardoso; SILVA, Jefferson Evaristo do Nascimento (Orgs.). PIBID, políticas públicas e ensino de Língua Portuguesa. Coleção Língua Portuguesa e Ensino. Volume 1. Rio de Janeiro: Dialogarts, 2017. p. 70-80.

CLEIN, Pamela Tais. Gênero crônica: oficina de elaboração textual na escola. Revista Práticas de Linguagem, v.7, n. 2, p. 287-295, 2007.

DUVIVIER, Gregório. Abraço Caudaloso. Folha de S. Paulo, 02 fev. 2015. Disponível em: https://m.folha.uol.com.br/colunas/gregorioduvivier/2015/02/1583811abracocaudaloso.shtml. Acesso em: 26 abr. 2019.

FERREIRA, Simone Cristina Salviano. A crônica: problemáticas em torno de um gênero. Uberlândia, 2005. Dissertação (Mestrado em Linguística). Programa de Pós-Graduação em Linguística, Universidade Federal de Uberlândia (MG), 2005.

INTERVENÇÃO. In: ENCICLOPÉDIA Itaú Cultural de Arte e Cultura Brasileiras. São Paulo: Itaú $\quad$ Cultural, 2019. Disponível em: http://enciclopedia.itaucultural.org.br/termo8882/intervencao. Acesso em: 06 ago. 2020. Verbete da Enciclopédia.

KUNZ, Marinês Andrea et al. O ensino de Língua Portuguesa e de Literatura no PIBIDLetras FEEVALE. Revista Conhecimento Online, v. 2, p. 155-166, set. 2011.

MENDONÇA, Márcia. Gêneros em projetos didáticos: processos de (des)legitimação no discurso de licenciandos do Programa Institucional de Bolsas de Iniciação à Docência. Cad. CEDES. Campinas, v. 38, n. 105, p. 240-259, maio-ago. 2018.

OLIVEIRA, Hélvio Frank. A bagagem do PIBID para a formação inicial docente e para a construção da identidade profissional. Trabalhos em Linguística Aplicada, Campinas, n. 56.3, p. 913-934, set./dez. 2017.

SÁ, Jorge de. A crônica. $3^{\text {a }}$ ed. São Paulo: Editora Ática S.A., 1985.

TÁVOLA, Artur da. Literatura de jornal (O que é a Crônica). Jornal O Dia, Rio de Janeiro, 27 jul. 2001. Disponível em: http://www.crmariocovas.sp.gov.br/ntc_l.php?t=044. Acesso em: 25 ago. 2020.

VERISSIMO, Luis Fernando. O melhor das comédias da vida privada. Rio de Janeiro: Editora Objetiva, 2004. 